\title{
Corticosteroids in acute respiratory distress syndrome
}

\section{A.B.S. Fernandes ${ }^{1}$, W.A. Zin ${ }^{2}$ and P.R.M. Rocco ${ }^{1}$}

\author{
Laboratórios de ${ }^{1}$ Investigação Pulmonar, and ${ }^{2}$ Fisiologia da Respiração, \\ Instituto de Biofísica Carlos Chagas Filho, Universidade Federal do Rio de Janeiro, \\ Rio de Janeiro, RJ, Brasil
}

Correspondence

P.R.M. Rocco

Laboratório de Investigação Pulmonar

Instituto de Biofísica Carlos

Chagas Filho, CCS, UFRJ

21949-900 Rio de Janeiro, RJ

Brasil

Fax: +55-21-2280-8193

E-mail: prmrocco@biof.ufr.jbr

Research supported by PRONEX-

MCT, CNPq and FAPERJ.

$\ldots \ldots \ldots \ldots \ldots \ldots$

Received April 12, 2004

Accepted December 8, 2004

$\ldots \ldots \ldots \ldots \ldots \ldots \ldots . . . .$.

\begin{abstract}
Improving the course and outcome of patients with acute respiratory distress syndrome presents a challenge. By understanding the immune status of a patient, physicians can consider manipulating proinflammatory systems more rationally. In this context, corticosteroids could be a therapeutic tool in the armamentarium against acute respiratory distress syndrome. Corticosteroid therapy has been studied in three situations: prevention in high-risk patients, early treatment with high-dose, short-course therapy, and prolonged therapy in unresolving cases. There are differences between the corticosteroid trials of the past and recent trials: today, treatment starts 2-10 days after disease onset in patients that failed to improve; in the past, the corticosteroid doses employed were 5140 times higher than those used now. Additionally, in the past treatment consisted of administering one to four doses every $6 \mathrm{~h}$ (methylprednisolone, $30 \mathrm{mg} / \mathrm{kg}$ ) versus prolonging treatment as long as necessary in the new trials $\left(2 \mathrm{mg} \mathrm{kg}^{-1}\right.$ day $^{-1}$ every $\left.6 \mathrm{~h}\right)$. The variable response to corticosteroid treatment could be attributed to the heterogeneous biochemical and molecular mechanisms activated in response to different initial insults. Numerous factors need to be taken into account when corticosteroids are used to treat acute respiratory distress syndrome: the specificity of inhibition, the duration and degree of inhibition, and the timing of inhibition. The major continuing problem is when to administer corticosteroids and how to monitor their use. The inflammatory mechanisms are continuous and cyclic, sometimes causing deterioration or improvement of lung function. This article reviews the mechanisms of action of corticosteroids and the results of experimental and clinical studies regarding the use of corticosteroids in acute respiratory distress syndrome.
\end{abstract}

\section{Introduction}

Effective management of acute respiratory distress syndrome (ARDS) has been problematic since this syndrome was first
Key words

- Acute respiratory distress syndrome

- Collagen

- Cytokine

- Methylprednisolone

- Experimental models

- Clinical trials 
graph. Although the term ARDS is often used interchangeably with acute lung injury, by strict criteria ARDS should be reserved for the most severe end of the spectrum. Acute lung injury is characterized by acute development of bilateral infiltrates detected on chest radiographs, pulmonary capillary wedge pressure of $18 \mathrm{mmHg}$ or less or the absence of clinically evident left atrial hypertension, and a ratio of partial pressure of arterial oxygen to the fraction of inspired oxygen $\left(\mathrm{PaO}_{2} / \mathrm{FiO}_{2}\right)$ of 300 or less. The definition of ARDS differs only by the presence of worsened oxygenation, represented by a $\mathrm{PaO}_{2} / \mathrm{FiO}_{2}$ ratio of 200 or less (2). Despite recent advances in the understanding of the pathophysiology of ARDS and improved life support of patients with ARDS, the mortality rates persist at 30 to $60 \%(3,4)$.

ARDS is thought to be a uniform expression of a diffuse and overwhelming inflammatory reaction of the pulmonary parenchyma to a variety of serious underlying diseases. In 1994, the American-European Consensus Conference (2) defined two pathogenetic pathways leading to ARDS as a direct ("primary" or "pulmonary") insult, that directly affects lung parenchyma, and an indirect ("secondary" or "extrapulmonary") insult, that results from an acute systemic inflammatory response $(5,6)$. The pathologic features of the lung in ARDS derive from severe injury to the alveolocapillary unit. The morphologic picture of the lung in ARDS has been labeled diffuse alveolar damage, and extravasations of intravascular fluid dominate the onset of the disease. Microscopic findings are dependent on the stage of the illness. Traditionally, ARDS has been divided into three stages in which an initial inflammatory phase (exudative) is followed by fibro-proliferation, which can lead to established interstitial and intra-alveolar fibrosis, the final phase. The histological features of the exudative phase are: a) hyaline membranes, b) alveolar collapse, and c) swollen type I pneumocytes with cytoplas- mic vacuoles. The endothelial cells swell, the intercellular junctions widen, and pinocytic vesicles increase, causing disruption in the capillary membrane and resulting in capillary leakage and edema formation (7). The proliferative phase has been described to begin as early as the third day but was most prominent in the second and third weeks after symptom onset. However, recently, some investigators have reported that fibro-proliferation is an early response to lung injury (8-10). Thus, inflammatory and repair mechanisms occur in parallel rather than in series. In the fibrotic phase, extensive remodeling of the lung by sparsely cellular collagenous tissue occurs, air spaces are irregularly enlarged and there is alveolar duct fibrosis. Type III collagen is replaced by type I collagen, leading to a stiff lung over time (7).

The recognition that neutrophils, macrophages, and other components of the inflammatory cascade participate in the progression of ARDS has resulted in the use of antiinflammatory agents, particularly glucocorticoids $(11,12)$. Although glucocorticoid treatment might increase the risk of infection, careful limited administration of the corticosteroid could promote the resolution of injured tissue $(13,14)$.

Corticosteroid therapy in ARDS has been studied in three main different situations: 1) prevention in high risk patients $(15,16), 2)$ early treatment with high-dose, short-course therapy (17), and 3) prolonged therapy in unresolving cases (18-22). It is clear that there is no evidence to support the use of corticosteroids for the prevention of ARDS in all patients at high risk. In addition, although there is intense inflammatory activity in the early stages of ARDS, early corticosteroid therapy similarly does not appear to be justified. The effects of corticosteroids have been investigated in unresolving ARDS. The failure of the beneficial effect of corticosteroids in the early phase of ARDS may be due to the population studied, in particular to the fact that those studies were multicentric 
ones, highly heterogeneous in term of case mix and of patient management. In addition, negative effects due to the profound immunodepression or other side effects induced by high doses of steroids could counterbalance positive effects, so that the overall effect could be neutral or even deleterious. Corticosteroid therapy would be ineffective if many of the patients who were considered to have ARDS based on clinical definitions did not develop activation of inflammatory cascades in their lungs.

This article reviews the mechanisms of action of corticosteroids and the results of experimental and clinical studies for the use of corticosteroids in ARDS.

\section{Mechanisms of action}

Cortisol is the predominant corticosteroid secreted by the adrenal cortex in humans. In a healthy, unstressed person, cortisol is secreted according to a diurnal pattern under the influence of corticotropin released from the pituitary gland. Corticotropin secretion, in turn, is under the influence of hypothalamic corticotropin-releasing hormone, and both hormones are subject to negative feedback control by cortisol itself. Circulating cortisol is bound to corticosteroid-binding globulin, with less than $10 \%$ in the free, bioavailable form. With severe infection, trauma, burns, illness, or surgery, there is an increase in cortisol production that is proportional to the severity of the illness. Additionally, diurnal variation in cortisol secretion is lost. These effects are due to increased production of corticotropin-releasing hormone and corticotropin and a reduction in negative feedback from cortisol. Stimulation of the hypothalamic-pituitary-adrenal axis is caused by elevated levels of circulating cytokines, among other factors (23).

Corticosteroids modulate the host defense response at virtually all levels, protecting the host from immune system overreaction. Corticosteroids are mainly transported in the blood complexed to transcortin (corticosteroid-binding globulin) and albumin, although a small portion is in a free, metabolically active state. The free corticosteroid molecules cross the plasma membrane into the cytoplasm, where they bind to a specific receptor, the glucocorticoid receptor (GR). The GR is located in the cytoplasm of nearly all human cells (14). After hormone binding, the GR complex migrates to the cell nucleus and inhibits inflammatory gene transcription, including nuclear factor (NF)- $\kappa \mathrm{B}$ and activator protein-1, which are activated by extracellular inflammatory signals received by cell surface receptors.

When not bound to its ligand, GR is sequestered in the cytoplasm as an inactive complex with two molecules of heat shock protein (HSP-90), and other cytosolic proteins. Upon binding glucocorticoids, GR undergoes conformational changes which allow it to dissociate from HSP-90 molecules. The hormone-bound GR translocates to the nucleus, where it transiently associates with another HSP, HSP-56, and later dissociates from it and binds as a dimer to conserved palindromic DNA sequences named glucocorticoid response elements (GRE; Figure 1) (24).

$\mathrm{NF}-\kappa \mathrm{B}$ is the central transcription factor that drives the inflammatory response to insults. It is found in essentially all cell types and is involved in activation of an exceptionally large number of target genes. NF- $\kappa \mathrm{B}$ activation is an essential step in the experimental development of neutrophilic lung inflammation (25).

$\mathrm{NF}-\kappa \mathrm{B}$ consists of two subunits arranged as homodimers or heterodimers. The most common form of activated NF- $\mathrm{KB}$ consists of a $p 65$ and $p 50$ heterodimer. Under basal conditions NF- $\mathrm{KB}$ is retained in the cytoplasm in an inactive state by a related inhibitory protein known as I $\mathrm{I} B \alpha$. Currently the most commonly accepted mechanism leading to the activation of $\mathrm{NF}-\mathrm{\kappa B}$ involves the activation of the recently described IкB kinase, 
which rapidly phosphorylates $\mathrm{I} \kappa \mathrm{B} \alpha$ in response to various pro-inflammatory signals such as endotoxin, tumor necrosis factor (TNF)- $\alpha$, IL-1 $1 \beta$, oxidants, bacteria, viruses, and phorbol esters. The liberated NF- $\kappa B$ then translocates into the nucleus and binds to promoter regions of target genes to initiate the transcription of multiple cytokines including TNF- $\alpha$, and the interleukins (IL)-1ß, IL-2, IL-6, chemokines such as IL-8, cell adhesion molecules, growth factors, interferon, receptors involved in immune recognition, proteins involved in antigen presentation, receptors required for neutrophil adhesion and migration, and inflammation-associated enzymes (25). Products of the genes that are stimulated by NF- $\kappa B$ activate this transcription factor. Thus, TNF- $\alpha$ and IL$1 \beta$ both activate and are activated by NF- $\mathrm{\kappa B}$ by forming a positive regulatory loop that amplifies and perpetuates the inflammation.

Activated GRs mediate transcriptional interference via the following mechanisms: a) by physically interacting with the $p 65$ subunit and forming an inactive GR $\alpha-\mathrm{NF}-\kappa \mathrm{B}$ complex, b) by inducing the transcription of the inhibitory protein I $\mathrm{B} \alpha$ gene, which traps

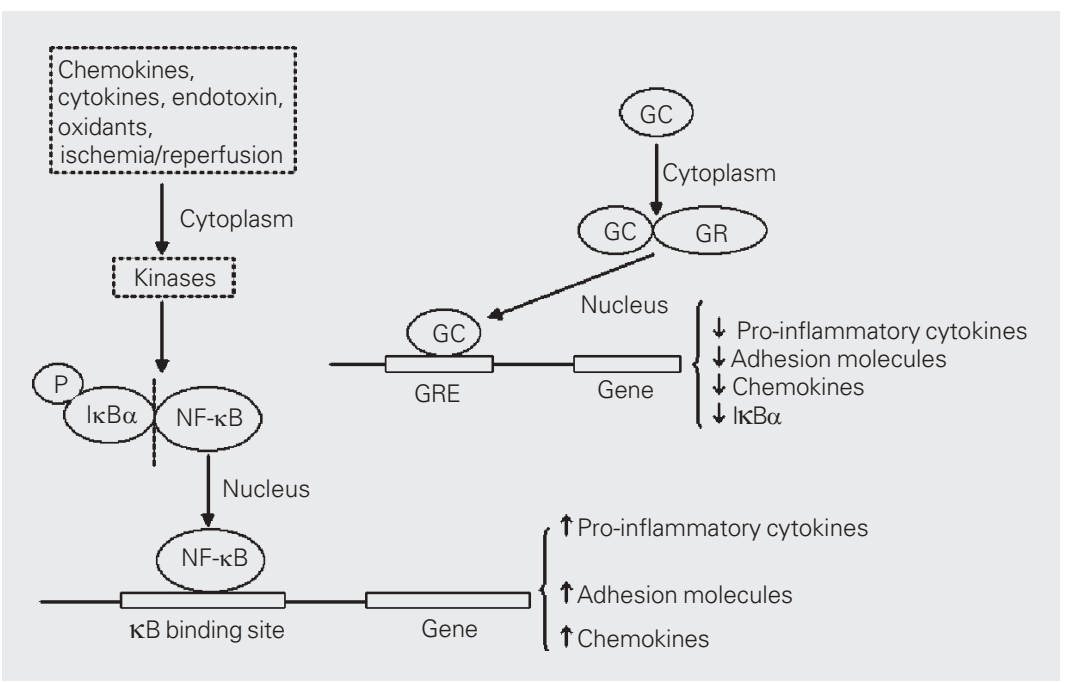

Figure 1. Mechanisms of action of corticosteroids. Glucocorticoids activate the cytoplasmic glucocorticoid receptor, which translocates to the nucleus and serves as an important

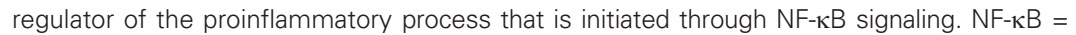

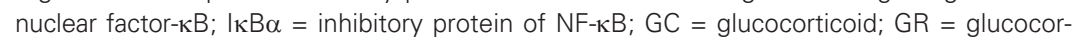
ticoid receptor; GRE = glucocorticoid response elements.
$\mathrm{NF}-\kappa \mathrm{B}$ in inactive cytoplasmic complexes catabolized by the ubiquitin-proteosoma pathway, c) by blocking degradation of IкB $\alpha$ via enhanced synthesis of IL-10, d) by impairing TNF- $\alpha$-induced degradation of $\mathrm{I} \kappa \mathrm{B} \alpha$, and e) by competing for limited amounts of GR coactivators $(26,27)$. GRs may also interact directly with protein transcription factors in the cytoplasm and nucleus and thereby influence the synthesis of certain proteins independently of an interaction with DNA in the cell nucleus.

The inhibitory effects of corticosteroids on cytokine synthesis are particularly important. Corticosteroids inhibit NF- $\kappa \mathrm{B}$ and consequently the expression of the NF- $\mathrm{KB}$-dependent proinflammatory gene (27). Thus, they inhibit the transcription of several cytokines that are relevant to ARDS, including IL-1, IL-3, IL-4, IL-5, IL-6, IL-8, TNF- $\alpha$, and granulocyte-macrophage colony-stimulating factor. Corticosteroids also have an inhibitory effect on fibrogenesis (18), and act on the antagonist of IL-1 receptor and on the anti-inflammatory cytokines IL-4, IL-10, and IL-13 (28) with synergy to control the host defense response. Glucocorticoids stimulate apoptosis of T-cells, eosinophils, and monocytes, inhibit neutrophil activation, and are important in maintaining endothelial integrity and vascular permeability (29).

The response of a single cell exposed to corticosteroids is the result of the interplay of the following factors: 1 ) the concentration of the free hormone; 2) the relative potency of the hormone (influenced by biological activity, affinity for the GR in the nucleus), and 3) the ability of the cell to receive and transduce the hormonal signal (30). The endogenous glucocorticoids are not always effective in suppressing life-threatening systemic inflammation, even though the degree of cortisolemia frequently correlates with severity of illness and mortality rate (25). Failure to suppress inflammation could be due to tissue resistance to corticosteroids, and inadequacy of the level and duration of endogenous 
glucocorticoid elevation (31). The increased blood cortisol levels in patients with sepsis may reflect a block of steroidal activity or transport as a consequence of the infection. In this situation, a small increase in blood levels with a low dose of exogenous corticosteroids was believed to be sufficient to facilitate the passage of steroids into host cells. In vitro studies have shown that cytokines may induce resistance to glucocorticoids by reducing GR binding affinity to cortisol and/or GREs (32). Since it is the receptor that ultimately controls the expression of pertinent genes, anything that affects its concentration or binding affinity, translocation to the nucleus, and/or final transactivating or transrepressing conformation can also influence the response of the cells to corticosteroids. If one of these factors is defective, the system does not respond properly.

The various corticosteroid preparations available for systemic use differ in their relative anti-inflammatory potency, potential for sodium retention, and plasma and biologic half-lives. In general, short-acting preparations such as prednisone and prednisolone are preferable to longer-acting agents such as dexamethasone because tapering to an alternate-day schedule cannot be accomplished with drugs with prolonged (i.e., $>24$ h) biologic half-lives. In addition, hydrocortisone and cortisone are rarely used to treat inflammatory and immunologically mediated diseases because of the considerable mineralocorticoid activity that accompanies their use. Methylprednisolone may be better concentrated in the lungs than prednisolone because it has a larger volume of distribution, longer mean residence time, and greater retention in the epithelial lining fluid of the alveoli (14).

\section{Animal research}

The results of animal studies have greatly increased our knowledge about lung injury, but considerable caution is necessary when extrapolating from experimental models to humans. In addition, results obtained from corticosteroid therapy in animal models with ARDS have been controversial.

A wide variety of animal models have been developed to explore the effects of corticosteroids on ARDS. Both direct and indirect insults to the alveolar-capillary membrane have been used in various animal species to model ARDS (33). Several studies using animal models of sepsis and lung injury have shown that corticosteroids decrease morbidity and mortality if given simultaneously with or before the experimental insult $(21,34)$. Pretreatment with corticosteroids was also shown to increase the survival rate in acute lung injury induced by aspiration pneumonitis and oleic acid-induced pulmonary edema $(35,36)$. In a rat model of butylated-hydroxytoluene-induced ARDS, the timing of corticosteroid administration had strikingly different effects. Early administration of steroids resulted in increased collagen deposition, increased lung damage, and inhibition of type II pneumocyte proliferation. Late administration, on the other hand, prevented excessive collagen deposition (33).

Systemic methylprednisolone or dexamethasone at doses of 20 or $4 \mathrm{mg} \mathrm{kg}^{-1}$ day $^{-1}$, respectively, improved pulmonary inflammation and mechanics in animals with acute lung injury $(36,37)$. On this basis, dexamethasone (a single dose of $2.5 \mathrm{mg} / \mathrm{kg}$ ) significantly reduced inflammatory cell protein content in bronchoalveolar lavage fluid (BALF), and improved lung compliance $24 \mathrm{~h}$ after injury induced by oleic acid (38).

Kuwabara and co-workers (39), however, showed that prophylactic treatment with methylprednisolone $\left(60 \mathrm{mg} \mathrm{kg}^{-1} \mathrm{~h}^{-1} 30\right.$ min before oleic acid infusion, followed by continuous infusion until the end of the experiments) did not attenuate oleic acidinduced acute lung injury or the increased level of phospholipase $A_{2}$ activity, leukotriene $\mathrm{B}_{4}$ and thromboxane $\mathrm{B}_{2}$ in the BALF, but 
greatly reduced IL-8 (39).

Corticosteroid at a dose of $10 \mathrm{mg} / \mathrm{kg}$, starting on day 5 after the infection with reovirus $1 / \mathrm{L}$, and given daily until the end of the time course of the disease, also did not attenuate the infiltration of inflammatory leukocytes, did not suppress key cytokine/ chemokine expression, and did not inhibit the development of fibrotic changes in the lungs (40).

Rocco and colleagues analyzed the effects of corticosteroids in the early phase of paraquat-induced acute lung injury (41). They observed that corticosteroids acted differently depending on the degree of acute lung injury, leading to a complete maintenance of normal tissue mechanics and collagen content in a mild lesion, whereas they minimized the changes in tissue impedance and extracellular matrix components in a severe lesion. In addition, the early beneficial effects of corticosteroids on extracellular matrix remained unchanged 30 days after paraquatinduced acute lung injury.

\section{Clinical trials}

\section{Early acute respiratory distress syndrome}

Based on results of animal research, methylprednisolone was subjected to clinical trials as adjunctive therapy for patients with ARDS (Table 1). Weigelt and colleagues (15) performed a prospective, double-blind, randomized study of early corticosteroid therapy on acutely ill, mechanically ventilated patients felt to be at high risk for ARDS. Of the 81 patients, 39 received intravenous methylprednisolone $(30 \mathrm{mg} / \mathrm{kg}$ every $6 \mathrm{~h}$ for $48 \mathrm{~h}$ ) and 42 received placebo. ARDS developed in significantly more methylprednisolone-treated patients (25/39 (51\%) and placebo, 14/42 (33\%)), but no significant differences in mortality were observed between these two groups.

At least three subsequent randomized controlled trials failed to show any protective effects of high dose corticosteroids in patients with sepsis at risk for $\operatorname{ARDS}(16,17,42)$.

Table 1. Clinical trials of glucocorticoids for the prevention of acute respiratory distress syndrome or for the treatment of the early phase of the disease.

\begin{tabular}{|c|c|c|c|}
\hline Reference & Population & Dose & Results \\
\hline $\begin{array}{l}\text { Schonfeld et al. } \\
\text { (44) }\end{array}$ & $\begin{array}{l}\text { Fat embolism } \\
\text { syndrome }\end{array}$ & $\begin{array}{l}\text { MP } 7.5 \mathrm{mg} / \mathrm{kg} \text { every } \\
6 \mathrm{~h} \times 12 \text { doses }\end{array}$ & $\begin{array}{l}\text { MP decreases the risk of } \\
\text { respiratory failure }\end{array}$ \\
\hline Weigelt et al. (15) & Septic shock & $\begin{array}{l}\text { MP } 30 \mathrm{mg} / \mathrm{kg} \text { every } \\
6 \mathrm{~h} \times 2 \text { days }\end{array}$ & $\begin{array}{l}\text { Greater progression to ARDS with } \\
\text { no change in mortality }\end{array}$ \\
\hline Luce et al. (42) & Septic shock & $\begin{array}{l}\text { MP } 30 \mathrm{mg} / \mathrm{kg} \text { every } \\
6 \mathrm{~h} \times 4 \text { days }\end{array}$ & $\begin{array}{l}\text { Similar progression to ARDS and } \\
\text { overall mortality rate for MP and } \\
\text { placebo groups }\end{array}$ \\
\hline Bernard et al. (17) & Established ARDS & $\begin{array}{l}\text { MP } 30 \mathrm{mg} / \mathrm{kg} \text { every } \\
6 \mathrm{~h} \times 4 \text { days }\end{array}$ & $\begin{array}{l}\text { Similar mortality rate for MP and } \\
\text { placebo groups }\end{array}$ \\
\hline Bone et al. (16) & Septic syndrome & $\begin{array}{l}\text { MP } 30 \mathrm{mg} / \mathrm{kg} \text { every } \\
6 \mathrm{~h} \times 4 \text { days }\end{array}$ & $\begin{array}{l}\text { MP impedes the reversal of ARDS } \\
\text { and increases the mortality rate }\end{array}$ \\
\hline Bozzette et al. (45) & $\begin{array}{l}\text { Pneumocystis carinii } \\
\text { pneumonia }\end{array}$ & $\begin{array}{l}\text { Prednisone } 40 \mathrm{mg} \text { every } \\
12 \mathrm{~h} \times 2 \text { doses }\end{array}$ & $\begin{array}{l}\text { Prednisone reduces the risks of } \\
\text { respiratory failure and death }\end{array}$ \\
\hline Gagnon et al. (46) & $\begin{array}{l}\text { Pneumocystis carinii } \\
\text { pneumonia }\end{array}$ & $\begin{array}{l}\text { MP } 40 \text { mg every } \\
6 \mathrm{~h} \times 7 \text { days }\end{array}$ & $\begin{array}{l}\text { MP improves survival and decreases } \\
\text { the occurrence of respiratory failure }\end{array}$ \\
\hline
\end{tabular}


Bone and colleagues (16) conducted a multicenter, double-blind, randomized controlled trial to determine whether corticosteroid therapy could prevent the development of ARDS in high-risk patients. The patients with sepsis received methylprednisolone $(30 \mathrm{mg} / \mathrm{kg})$ or placebo infusions every $6 \mathrm{~h}$ for a total of four doses. Treatment was initiated within $2 \mathrm{~h}$ of the onset of sepsis. There was an increased incidence of ARDS in the steroid group. In those patients developing ARDS, 14-day mortality was significantly higher in the steroid group than in the placebo group. As in the studies of Bone and co-workers (16), the results of a clinical trial conducted by Luce and colleagues (42) failed to demonstrate any benefit of corticosteroid on ARDS development or subsequent death. These investigators conducted a prospective, double-blind, randomized trial evaluating the efficacy of steroid in preventing ARDS in patients with septic shock. Patients received four doses of methylprednisolone ( $30 \mathrm{mg} / \mathrm{kg}$ every $6 \mathrm{~h}$ ) or placebo. In the steroid group, 13 of 38 patients $(34 \%)$ developed ARDS compared with 14 of $37(38 \%)$ in the placebo group. Mortality was $58 \%$ in the steroid group versus $54 \%$ in the placebo group. Thus, it is clear that there is no evidence to support the use of corticosteroids for the prevention of ARDS in all patients at high risk.

In 1987, Bernard and colleagues (17) performed a double-blind, randomized controlled trial to determine the effect of highdose, short-course corticosteroid on mortality and several physiological variables in early ARDS. They studied adult patients who met ARDS criteria (2) and excluded those with recent corticosteroid use, evidence of active infection, another indication for corticosteroids, extensive burns, or pregnancy. They randomized 99 adult patients within $30 \mathrm{~h}$ of the onset of ARDS to receive high-dose methylprednisolone or placebo. They observed that corticosteroid had no effect on oxygenation, hemodynamics, ARDS reversal, or mortality. In addition, there was a trend toward increased infections in the corticosteroid group, as well as significantly treatment-related hyperglycemia. There is no evidence of benefit from a short-course of high-dose therapy early in the course of ARDS.

It is not surprising that corticosteroid will not be effective as ARDS therapy. This failure could be due to the population under study, in particular to the fact that those studies were multicentric ones, highly heterogeneous in terms of case mix and patient management. The effect of the corticosteroids could indeed be very different according to the dosage used. In addition, negative effects due to profound immunodepression or other side effects induced by high doses of steroids could counterbalance positive effects, so that the overall effect could be neutral or even deleterious. While such disappointing results may be due to the "wrong" mediator being targeted, another possibility is the heterogeneity of pulmonary processes in patients included in clinical trials. In addition, corticosteroid therapy may be ineffective if many of the patients that were considered to have ARDS based on clinical definitions do not have activation of inflammatory cascades in their lungs. Donnelly and Bucala (43) presented other evidence that may explain why corticosteroids fail in early ARDS (43). Macrophage inhibitor factor has been shown to override corticosteroid-mediated inhibition of cytokine secretion. Interestingly, macrophage inhibitor factor is present in the BALF of ARDS patients and enhances both TNF- $\alpha$ and IL- 8 secretion by alveolar macrophages from ARDS patients. Thus, macrophage inhibitor factor may act as a mediator that promotes and sustains the pulmonary inflammatory response in ARDS, and thus may explain, in part, why glucocorticoids have been ineffective in the acute phase of ARDS.

Corticosteroids have been shown to reduce mortality in two groups of patients with ARDS or at risk for developing the syn- 
drome. The first includes patients at risk for fat embolism syndrome, in whom corticosteroids given prophylactically have been shown to decrease the risk of respiratory failure. Schonfeld and co-workers (44) randomly assigned 64 consecutive patients who had one or more lower-extremity, long-bone fractures to receive intravenous placebo or methylprednisolone $(7.5 \mathrm{mg} / \mathrm{kg}$ every $6 \mathrm{~h}$ for 12 doses, total dose of $90 \mathrm{mg} / \mathrm{kg}$ ). One of the patients who received placebo died, whereas none of the patients who received corticosteroid died. Nine of the patients who received placebo developed fat embolism syndrome, which was associated with alveolar infiltrates in three of them, whereas none of the patients who received methylprednisolone developed fat embolism syndrome with or without infiltration. These data support the value of high-dose corticosteroids in patients at risk for the fat embolism syndrome.

The second group of patients with ARDS or at risk for developing the syndrome, who benefit from corticosteroids, are those with AIDS and Pneumocystis carinii pneumonia. Two randomized trials have assessed the efficacy of adjunctive therapy with corticosteroids in patients with AIDS and pneumonia $(45,46)$. Patients in these studies received placebo or a combination of intravenous and oral corticosteroids when pneumonia initially was treated with antibiotics. The active drugs were associated with diminished respiratory deterioration, improved survival, or both, in all three studies.

\section{Late acute respiratory distress syndrome}

In contrast to early ARDS, there is evidence that corticosteroids may be beneficial in the fibroproliferative phase, or late phase of ARDS (Table 2). Ashbaugh and Maier (47) described 10 patients who did not respond to conventional treatment. These patients underwent open-lung biopsies, and histological examination showed that all had cellular proliferation, obliteration of alveoli, and fibrosis without infection. Patients were treated with intravenous methylprednisolone (125 mg every $6 \mathrm{~h}$ ) beginning 6 to 22 days after onset of ARDS, followed by oral prednisolone tapered over 3 to 6 weeks. Eight patients recovered and 2 died of sepsis. Hooper and Kearl (48) studied the effects of corticosteroids in 10 patients who survived the early phase of ARDS. ARDS was present 3 to 40 days before steroid therapy. The initial dose of methylprednisolone (125 to $250 \mathrm{mg}$ every $6 \mathrm{~h}$ ) was based on the severity

Table 2. Clinical trials of glucocorticoids in the late phase of acute respiratory distress syndrome.

\begin{tabular}{|c|c|c|c|}
\hline Reference & Population & Dose & Results \\
\hline Ashbaugh and Maier (47) & $\begin{array}{l}\text { Idiopathic pulmonary } \\
\text { fibrosis }\end{array}$ & MP 125 mg every $6 \mathrm{~h}$ & MP increases survival \\
\hline Hooper and Kearl (48) & Established ARDS & $\begin{array}{l}\text { MP } 125 \text { to } 250 \mathrm{mg} \\
\text { every } 6 \mathrm{~h}\end{array}$ & $\begin{array}{l}\text { MP improves the } \\
\text { respiratory parameters }\end{array}$ \\
\hline Meduri et al. (50) & Established ARDS & $\begin{array}{l}\text { MP } 200 \mathrm{mg} \text { followed } \\
\text { by } 2 \text { to } 3 \mathrm{mg} \mathrm{kg}^{-1} \text { day }^{-1} \\
\text { every } 6 \mathrm{~h} \text { until extubation }\end{array}$ & $\begin{array}{l}\mathrm{MP} \text { increases the } \mathrm{PaO}_{2} / \mathrm{FiO}_{2} \\
\text { ratio and decreases LIS }\end{array}$ \\
\hline Meduri et al. (52) & Established ARDS & $\begin{array}{l}\text { MP } 2 \mathrm{mg} / \mathrm{kg} \text { followed by } \\
2 \mathrm{mg} \mathrm{kg}^{-1} \text { day }^{-1} \text { from day } \\
1 \text { to } 14 \text { every } 6 \mathrm{~h}\end{array}$ & $\begin{array}{l}\text { Changes in } \mathrm{PaO}_{2} / \mathrm{FiO}_{2} \text { ratio, } \\
\text { mean pulmonary artery } \\
\text { pressure, and MODS score }\end{array}$ \\
\hline
\end{tabular}

These clinical trials suggest a beneficial effect of prolonged use of glucocorticoids in late ARDS. ARDS = acute respiratory distress syndrome; MP = methylprednisolone; LIS = lung injury score; MODS = multiple-organ dysfunction syndrome. 
of respiratory involvement, and was maintained for 72 to $96 \mathrm{~h}$. All patients showed improvement in respiratory parameters. Overall survival was $81 \%$. Biffl and co-workers (49) used methylprednisolone (1 to $2 \mathrm{mg} / \mathrm{kg}$ every $6 \mathrm{~h}$ ) in 6 patients with refractory late ARDS. Steroids were instituted after 16 days of mechanical ventilatory support. By day 7 of steroid therapy, there was a clinically significant improvement in the ratio of arterial oxygen pressure to fraction of inspired oxygen $\left(\mathrm{PaO}_{2} / \mathrm{FiO}_{2}\right)$ and a decrease in lung injury score. Overall survival was $83 \%$ and the mean duration of corticosteroid therapy was 21.3 days.

A large uncontrolled series of patients with late ARDS treated with corticosteroids was studied by Meduri and colleagues $(18,50)$. They initially described 8 patients followed by an additional 17 patients. All patients had progressively worsening respiratory failure 7 days or more after the onset of ARDS. Patients were treated with methylprednisolone (200 $\mathrm{mg}$ in bolus followed by 2 to $3 \mathrm{mg}$ $\mathrm{kg}^{-1}$ day $^{-1}$ in divided doses every $6 \mathrm{~h}$ until extubation, after which the steroid was tapered slowly). By day 7 of treatment, the $\mathrm{PaO}_{2} / \mathrm{FiO}_{2}$ ratio increased and lung injury score decreased (50). Three patterns of response were noted: a) rapid responders showed improvement by day $7, b$ ) delayed responders showed improvement by day 14 , and c) nonresponders exhibited no improvement by day 14 . Overall survival rate was $72 \%$. Intensive care unit survival was $87 \%$ among rapid responders, $83 \%$ among delayed responders, and 25\% among nonresponders. The average duration of corticosteroid treatment was 36 days. Pneumonia developed in $38 \%$ of responders and $75 \%$ of nonresponders.

According to Meduri et al. (51), a comparison of physiological data with cytokine levels over time may explain the differences between responders and nonresponders. The rate of improvement in lung function during treatment may be related to the magnitude of the inflammatory response at initiation of corticosteroid therapy. After initiation of treatment, nonresponders had significantly worse lung function. Although nonresponders had a cytokine profile at initiation of treatment similar to the one of delayed responders, the behavior of IL-6 at the onset of ARDS was significantly different. Third, during corticosteroid therapy, improvements occurred in gas exchange, lung mechanics, and indices of increased endothelial permeability parallel to reductions in both plasma and bronchoalveolar lavage TNF- $\alpha$, IL-1ß, IL-6, and IL-8 levels.

In 1998, Meduri and co-workers (52) speculated that the early removal of high dose corticosteroid treatment in the previous randomized trials, which used short-term corticosteroid treatment, might have reversed any early beneficial effect of treatment or overturned the ability to detect a beneficial effect. In order to determine the effects of prolonged steroid therapy on lung function and mortality in non-resolving ARDS, they conducted a randomized, double-blind, placebo-controlled trial in four medical intensive care units. Twenty-four patients who fulfilled criteria for the diagnosis of ARDS (2) had been mechanically ventilated for 7 days and had no evidence of untreated infection. Sixteen patients were randomized to treatment with methylprednisolone while eight patients received placebo. The methylprednisolone dose was initially $2 \mathrm{mg} / \mathrm{kg}$ administered intravenously followed by $2 \mathrm{mg} \mathrm{kg}^{-1}$ day $^{-1}$ from day 1 to day 14 and then by progressively lower doses until day 32 of the study. One fourth of the total daily methylprednisolone dose was given every $6 \mathrm{~h}$. Significant changes were observed in $\mathrm{PaO}_{2} /$ $\mathrm{FiO}_{2}$ ratio, lung injury score, mean pulmonary artery pressure, and multiple-organ dysfunction syndrome score in the corticosteroid-treated group versus the placebo group. Intensive care unit survival was $100 \%$ in the steroid group versus $37 \%$ in the placebo group, and overall survival was 87 
versus $37 \%$, respectively.

Meduri (53) hypothesized that if endogenous glucocorticoid inadequacy and/or peripheral tissue resistance were important pathophysiologic factors in a deregulated, protracted systemic inflammatory response in ARDS, then prolonged glucocorticoid therapy might be useful, not as an anti-inflammatory treatment per se, but as hormonal supplementation necessary to compensate for the host's inability to produce appropriately elevated amounts of cortisol in relation to the degree of peripheral glucocorticoid resistance.

The host defense response to insults is similar regardless of the tissue involved and results from an interactive network of specialized and interconnected pathways that act in synergy to increase the host's chance of survival. Meduri (54) reviewed the host defense response in the progression of ARDS and how this response may be affected by corticosteroid therapy. Continued elevated production of host defense response mediators, such as TNF- $\alpha$, IL-1ß, and IL-6 prevents effective restoration of lung anatomy and function by sustaining inflammation, coagulation and fibro-proliferation resulting in fibrosis $(55,56)$. The degree of initial host defense response may determine the progress of ARDS. In another study by Meduri and co-workers (51), the effects of corticosteroid treatment on plasma and BALF cytokine levels in 9 patients with late ARDS were compared with 12 previous non-survivors from ARDS, who had undergone cytokine concentration measurements. Baseline plasma and BALF cytokine levels in the corticosteroid-treated patients were similar to those of the other group. The surviving patients treated with corticosteroids were found to have significant reductions in plasma and BALF TNF- $\alpha$, IL-1 $1 \beta$, IL- 6 , and IL-8 concentrations. The decreases in various cytokine levels were seen only after 5 to 14 days of steroid administration. On the other hand, ARDS non-survivors have been reported to have higher initial and persistent elevation of plasma and BALF cytokines compared with survivors. These findings mandate a reappraisal of the role of anti-inflammatory treatment of ARDS (51).

Ineffective lung repair in patients with unresolving ARDS is accompanied by progressive fibro-proliferation, inability to improve lung injury score, progressive multiple organ dysfunction syndrome, and an unfavorable outcome. Meduri and co-workers (57) also examined the effects of corticosteroids on plasma and BALF levels of procollagen aminoterminal propeptide type I (PINP) and type III (PIIINP) in patients with nonresolving ARDS. PINP and PIIINP are secreted by fibroblasts and reflect collagen synthesis at the site of disease. Previous studies reported that non-survivors of ARDS had persistent elevations of plasma and BALF PIIINP levels $(58,59)$. Meduri and co-workers (57) found elevated plasma levels of PINP and PIIINP in their patients at the time of study enrollment and observed that the concentrations of PINP and PIIINP increased over time in non-survivors, as opposed to survivors whose levels did not change significantly. Bronchoalveolar lavage concentrations of PINP and PIIINP were also noted to be higher in non-survivors compared with survivors, although the differences were not statistically significant. In that study 11 patients who had not shown an improvement in lung injury score greater than 1 point were randomized to receive methylprednisolone using the same protocol as in their previous randomized trial (52), and six patients received placebo. Patients treated with methylprednisolone showed significant decreases in plasma and BALF PINP and PIIINP levels, whereas no changes in these concentrations were seen in patients receiving placebo. Decreases in plasma and BALF PINP and PIIINP levels correlated with improvements in lung injury score and $\mathrm{PaO}_{2} / \mathrm{FiO}_{2}$ ratio.

Recently, Meduri and co-workers (60) investigated whether unresolving ARDS is associated with systemic inflammation-in- 
duced glucocorticoid resistance and whether prolonged methylprednisolone administration accelerates the suppression of systemic inflammatory indices and normalizes the sensitivity of the immune system to glucocorticoids. Patients enrolled into a randomized trial evaluating prolonged methylprednisolone administration in unresolving ARDS had serial plasma samples collected before and after randomization. Patients treated with corticosteroid had progressive and sustained reductions of TNF- $\alpha$, IL-1ß, IL- 6 , ACTH, and cortisol concentrations over time. Normal peripheral blood leukocytes exposed to plasma samples collected during methylprednisolone treatment also exhibited rapid and progressive significant increases in GR$\alpha$-mediated activities and significant reductions in NF- $\mathrm{KB}$ binding and transcription of TNF- $\alpha$ and IL-1ß. These findings provide support for the presence of endogenous glucocorticoid inadequacy in the control of inflammation and systemic inflammationinduced peripheral glucocorticoid resistance in ARDS. Prolonged methylprednisolone administration accelerated the resolution of both systemic inflammation and peripheral acquired glucocorticoid resistance in ARDS.

The variable response of ARDS to corticosteroid treatment could be attributed to the heterogeneous biochemical and molecular mechanisms of the different initial insults. Furthermore, numerous important factors need to be taken into account when corticosteroid is used as a strategy to treat ARDS: the specificity of inhibition, the duration and degree of inhibition, and the timing of inhibition. Predictors of poor outcome in ARDS are manifestations of a persistent and exaggerated host defense response. Suppression of this inflammatory response may lead to resolution of ARDS. Continued elevated production of host defense response mediators, such as TNF- $\alpha$, IL- $1 \beta$, and IL- 6 , prevents effective restoration of lung anatomy and function by sustaining inflammation, coagulation and fibro-proliferation. The degree of initial host defense response may determine the progress of ARDS. Spontaneous or treatment-induced suppression of the exaggerated and autonomous pulmonary host defense response is associated with improvement in lung function and outcome. Thereafter, excessive inflammatory activity in patients with sepsis, septic shock, or ARDS may induce noncompensated glucocorticoid resistance in target organs, thereby negating the beneficial suppressive influence of an inadequately secreted endogenous cortisol on the deregulated host defense response. Treatment with exogenous glucocorticoids may be necessary to compensate adequately for the inability of target organs to respond to endogenous cortisol and for the inability of the host to produce appropriately elevated levels of corticosteroids.

In conclusion, improving the course and outcome of patients with ARDS presents a considerable challenge. An important component of meeting this challenge is a more comprehensive understanding of the heterogeneous pathophysiology of ARDS and the biological response of the individual patient. By understanding the immune status of a given patient at a given point in the disease process, physicians can consider manipulating proinflammatory systems more rationally. Thus, ARDS need to be strongly reconsidered as a consistent response to its diverse etiology. The great problem remains the time when to start the use of a corticosteroid and, mainly, how to monitor its use. The inflammatory mechanisms are continuous and cyclic, sometimes causing deterioration or improvement of lung function. Experimental models have shown that treatment with a single low-dose of methylprednisolone in the early phase of acute lung injury might help prevent fibroelastogenesis, avoiding the side effects related to prolonged and high doses of steroid. Thus, these experimental studies may help the design of a clinical trial focused on diminishing lung injury with steroids. 


\section{References}

1. Ashbaugh DG, Bigelow DB, Petty TL \& Levine BE (1967). Acute respiratory distress syndrome. Lancet, 2: 319-323.

2. Bernard GR, Artigas A, Bringham KL, Carlet J, Falke K, Hudson L, Lamy M, Legall JR, Morris A \& Spragg R (1994). The AmericanEuropean consensus conference on ARDS: definitions, mechanisms, relevant outcomes, and clinical trial coordination. American Journal of Respiratory and Critical Care Medicine, 149: 818-824.

3. Kallet RH (2004). Evidence-based management of acute lung injury and acute respiratory distress syndrome. Respiratory Care, 49: 793-809.

4. Crimi E \& Slutsky AS (2004). Inflammation and the acute respiratory distress syndrome. Best Practice \& Research. Clinical Anaesthesiology, 18: 477-492.

5. Hoelz C, Negri EM, Lichtenfels AJ, Concecao GM, Barbas CS, Saldiva PH \& Capelozzi VL (2001). Morphometric differences in pulmonary lesions in primary and secondary ARDS. A preliminary study in autopsies. Pathology, Research and Practice, 197: 521530.

6. Pelosi P, Gamberoni C, Aspesi M, Severgnini P, Chiumello D, Caironi P, Chiaranda L \& Gattinoni L (2003). Pulmonary and extrapulmonary forms of acute respiratory distress syndrome are different? European Respiratory Journal, 22 (Suppl II): II-48-II-56.

7. Tomashefski Jr JF (2000). Pulmonary pathology of acute respiratory distress syndrome. Clinics in Chest Medicine, 21: 435-466.

8. Chesnutt AN, Matthay MA, Tibayan FA \& Clark JG (1997). Early detection of type III procollagen peptide in acute lung injury. Pathogenic and prognostic significance. American Journal of Respiratory and Critical Care Medicine, 156: 840-845.

9. Pugin J, Verghese G, Widmer MC \& Matthay MA (1999). The alveolar space is the site of intense inflammatory and profibrotic reactions in the early phase of acute respiratory distress syndrome. Critical Care Medicine, 27: 304-312.

10. Marshall RP, Bellingan G, Webb S, Puddicombe A, Goldsack N, McAnulty RJ \& Laurent GJ (2000). Fibro-proliferation occurs early in the acute respiratory distress syndrome and impacts on outcome. American Journal of Respiratory and Critical Care Medicine, 162: 1783-1788

11. Luce JM (2002). Corticosteroids in ARDS. An evidence-based review. Critical Care Clinics, 18: 79-89.

12. Brower RG, Ware LB, Berthiaume $Y$ \& Matthay MA (2001). Treatment of ARDS. Chest, 120: 1347-1367.

13. Tasaka S, Hasegawa N \& Ishizaka A (2002). Pharmacology of acute lung injury. Pulmonary Pharmacology and Therapeutics, 15: 83-95.

14. Jantz MA \& Sahn AS (1999). Corticosteroids in acute respiratory failure. American Journal of Respiratory and Critical Care Medicine, 160: $1079-1100$.

15. Weigelt JA, Norcross JR, Borman KR \& Snyder WH (1985). Early steroid therapy for respiratory failure. Archives of Surgery, 120: 536-540.

16. Bone RC, Fisher Jr CJ, Clemmer TP, Slotman GJ \& Metz CA (1987). Early methylprednisolone treatment for septic syndrome and the adult respiratory distress syndrome. Chest, 92: 10321036.

17. Bernard GR, Luce JM, Sprung CL, Rinaldo JE, Tate RM, Sibbald WJ, Kariman K, Higgins S, Bradley R \& Metz CA (1987). High dose corticosteroids in patients with the adult respiratory distress syndrome. New England Journal of Medicine, 317: 1565-1570.

18. Meduri GU, Belenchia JM, Estes RJ, Wunderink RG, el Torky M \& Leeper Jr KV (1991). Fibroproliferative phase of ARDS: clinical findings and effects of corticosteroids. Chest, 100: 943-952.

19. Demling RH, Proctor R, Grossman J, Duy N \& Starling J (1980). Comparison of the systemic and pulmonary vascular response to endotoxin with plasma and lung lymph lysosomal enzyme release: effect of steroid pretreatment. Circulatory Shock, 7: 317-331.

20. Brigham KL, Bowers RE \& McKeen CR (1981). Methylprednisolone prevention of increased lung vascular permeability following endotoxemia in sheep. Journal of Clinical Investigation, 67: 11031110.

21. Thomas CS \& Brockman SK (1968). The role of adrenal corticosteroid therapy in Escherichia coli endotoxin shock. Surgery, Gynecology and Obstetrics, 126: 61-69.

22. Wertzberger JJ \& Peltier LF (1968). Fat embolism: the effect of corticosteroids on experimental fat embolism in the rat. Surgery, 64: 143-147.

23. Cooper MS \& Stewart PM (2003). Corticosteroid insufficiency in acutely ill patients. New England Journal of Medicine, 348: 727734.

24. Almawi WY \& Melemedjian OK (2002). Negative regulation of nuclear factor-kappaB activation and function by glucocorticoids. Journal of Molecular Endocrinology, 28: 69-78.

25. Meduri GU, Carratu P \& Freire AX (2003). Evidence of biological efficacy for prolonged glucocorticoid treatment in patients with unresolving ARDS. European Respiratory Journal, 42 (Suppl I): I57-I-64.

26. Payne DNR \& Adcock IM (2001). Molecular mechanisms of corticosteroid actions. Paediatric Respiratory Review, 2: 145-150.

27. Wissink $S$, van Heerde EC, vand der Burg B \& van der Saag PT (1998). A dual mechanism mediates repression of NF-kappa B activity by glucocorticoids. Molecular Endocrinology, 12: 355-363.

28. Hart PH, Whitty GA, Burgess DR, Croatto M \& Hamilton JA (1990). Augmentation of glucocorticoid action on human monocytes by interleukin-4. Lymphokine Research, 9: 147-153.

29. Thompson BT (2003). Glucocorticoids and acute lung injury. Critical Care Medicine, 31: 5253-5257.

30. Bamberger CM, Shulte HM \& Chrousos GP (1996). Molecular determinants of glucocorticoid function and tissue sensitivity to glucocorticoids. Endocrine Reviews, 17: 245-261.

31. Briegel J, Forst $H$, Hellinger $H$ \& Haller M (1991). Contribution of cortisol deficiency to septic shock. Lancet, 338: 507-508.

32. Almawi WY, Lipman ML, Stevens AC, Zanker B, Hadro ET \& Strom TB (1991). Abrogation of glucocorticoid-mediated inhibition of $T$ cell proliferation by the synergistic action of IL-1, IL-6, and IFNgamma. Journal of Immunology, 146: 3523-3527.

33. Jones RJ \& King RG (1975). The effects of methylprednisolone on oxygenation in experimental hypoxemic respiratory failure. Journal of Trauma, 15: 297-303.

34. White GI, Archer LJ, Beller BK \& Hinshaw LB (1978). Increased survival with methylprednisolone treatment in canine endotoxin shock. Journal of Surgical Research, 25: 357-364.

35. Lawson DW, Defalco AJ, Phelps JA, Bradley BE \& McClenathan JE (1966). Corticosteroids as treatment for aspiration of gastric contents: an experimental study. Surgery, 59: 845-852.

36. Shiue ST \& Thrall RS (1991). Effect of corticosteroid therapy on the acute injury and recovery stage of oleic acid induced lung injury in the rat. Experimental Lung Research, 17: 629-638.

37. Cheney FW, Hung TH \& Gronka R (1979). Effects of methylprednisolone on experimental pulmonary injury. Annals of Surgery, 190: 236-242. 
38. Volpe BT, Lin W \& Thrall RS (1994). Effect of intratracheal dexamethasone on oleic acid-induced lung injury in the rat. Chest, 106: 583-587.

39. Kuwabara K, Furue S, Tomita Y et al. (2001). Effect of methylprednisolone on phospholipase A2 activity and lung surfactant degradation in acute lung injury in rats. European Journal of Pharmacology, 433: 209-216.

40. London L, Majeski E, Altman-Hamamdzic S, Enockson C, Paintlia MK, Harley RA \& London SD (2002). Respiratory Reovirus 1/L induction of diffuse alveolar damage: pulmonary fibrosis is not modulated by corticosteroids in acute respiratory distress syndrome in rats. Clinical Immunology, 103: 284-295.

41. Rocco PRM, Souza AB, Faffe DS, Passaro CP, Santos FB, Negri EM, Lima JG, Contador RS, Capelozzi VL \& Zin WA (2003). Effect of corticosteroid on lung parenchyma remodeling at an early phase of acute lung injury. American Journal of Respiratory and Critical Care Medicine, 168: 677-684

42. Luce JM, Montgomery AB, Marks JD, Turner J, Metz CA \& Murray JF (1988). Ineffectiveness of high-dose methylprednisolone in preventing parenchymal lung injury and improving mortality in patients with septic shock. American Review of Respiratory Disease, 138: 62-68.

43. Donnelly SC \& Bucala R (1997). Macrophage migration inhibitory factor: a regulator of glucocorticoid activity with a critical role in inflammatory disease. Molecular Medicine Today, 3: 502-507.

44. Schonfeld SA, Ploysongsang Y, DiLisio R, Crissman JD, Miller E, Hammerschmidt DE \& Jacob HS (1983). Fat embolism prophylaxis with corticosteroids: a prospective study in high risk patients. Annals of Internal Medicine, 99: 438-443.

45. Bozzette SA, Sattler FR, Chiu J, Wu AW, Gluckstein D, Kemper C, Bartok A, Niosi J, Abramson I \& Coffman J (1990). A controlled trial of early adjunctive treatment with corticosteroids for Pneumocystis carinii pneumonia in the acquired immunodeficiency syndrome. New England Journal of Medicine, 323: 1451-1457.

46. Gagnon S, Boota AM, Fischl MA, Baier H, Kirksey OW \& La Voie L (1990). Corticosteroids as adjunctive therapy for severe Pneumocystis carinii pneumonia in the acquired immunodeficiency syndrome: A double-blind, placebo-controlled trial. New England Journal of Medicine, 323: 1444-1450.

47. Ashbaugh DG \& Maier RV (1985). Idiopathic pulmonary fibrosis in adult respiratory distress syndrome. Diagnosis and treatment. Archives of Surgery, 120: 530-535.

48. Hooper RG \& Kearl RA (1990). Established ARDS treated with a sustained course of adrenocortical steroids. Chest, 97: 138-143.

49. Biffl WL, Moore FA, Moore EE, Haenel JB, Mclntyre Jr RC \& Burch JM (1995). Are corticosteroids salvage therapy for refractory acute respiratory distress syndrome? American Journal of Surgery, 170: 591-596.
50. Meduri GU, Chinn AJ, Leeper KV, Wunderink RG, Tolley E, WinerMuram HT, Khare V \& Eltorky M (1994). Corticosteroid rescue treatment of progressive fibro-proliferation in late ARDS: patterns of response and predictors of outcome. Chest, 105: 1516-1527.

51. Meduri GU, Headley S, Tolley E, Shelby M, Stentz F \& Postlethwaite A (1995). Plasma and BAL cytokine response to corticosteroid rescue treatment in late ARDS. Chest, 108: 1315-1325.

52. Meduri GU, Headley S, Golden E, Wunderink RG, Tolley E, WinerMuram HT, Khare V \& Eltorky M (1998). Effect of prolonged methylprednisolone therapy in unresolving acute respiratory distress syndrome: a randomised controlled trial. Journal of the American Medical Association, 280: 159-165.

53. Meduri GU (1999). A historical review of glucocorticoid treatment in sepsis: disease pathophysiology and the design of treatment investigation. Sepsis, 3: 21-28.

54. Meduri GU (1996). The role of the host defense response in the progression and outcome of ARDS: pathophysiologic correlations and response to glucocorticoid treatment. European Respiratory Journal, 9: 2650-2670.

55. Meduri GU, Headly S, Kohler G, Stentz F, Tolley E, Umberger R \& Leeper K (1995). Persistent elevation of inflammatory cytokines predicts a poor outcome in ARDS: plasma IL-1ß and IL-6 are consistent and efficient predictors of outcome over time. Chest, 107: 1062-1073.

56. Meduri GU, Kohler G, Headley S, Tolley E, Stentz F \& Postlethwaite A (1995). Inflammatory cytokines in the BAL of patients with ARDS: persistent elevation over time predicts poor outcome. Chest, 108: 1303-1314.

57. Meduri GU, Tolley EA, Chinn A, Stentz F \& Postlethwaite A (1998). Procollagen types I and III aminoterminal propeptide levels during acute respiratory distress syndrome and in response to methylprednisolone treatment. American Journal of Respiratory and Critical Care Medicine, 158: 1432-1441.

58. Entzian P, Huckstadt A, Kreipe H \& Barth J (1990). Determination of serum concentrations of type III procollagen peptide in mechanically ventilated patients: pronounced augmented concentrations in the adult respiratory distress syndrome. American Review of Respiratory Disease, 142: 1079-1082.

59. Clark JG, Milberg JA, Steinberg KP \& Hudson LD (1995). Type III procollagen peptide in the adult respiratory distress syndrome. Annals of Internal Medicine, 122: 17-23.

60. Meduri GU, Tolley EA, Chrousos GP \& Stentz F (2002). Prolonged methylprednisolone treatment suppresses systemic inflammation in patients with unresolving acute respiratory distress syndrome. Evidence for inadequate endogenous glucocorticoid secretion and inflammation-induced immune cell resistance to glucocorticoids. American Journal of Respiratory and Critical Care Medicine, 165: 983-991. 